\title{
The proportion of general practitioner referrals to a hospital Respiratory Medicine clinic suitable to be seen in a GPwSI Respiratory Clinic
}

\author{
Richard Gilbert ${ }^{\mathrm{a}, \mathrm{b}, *}$, Gaye Franks ${ }^{\mathrm{c}}$, Simon Watkin ${ }^{\mathrm{b}}$
}

\author{
a Castle Partnership, 29 Mile End Road, Norwich, NR2 3QR, UK \\ b Department of Respiratory Medicine, Norfolk and Norwich University Hospital, Colney Lane, \\ Norwich NR4 7UY, UK \\ ' Department of Clinical Audit and Quality, Norfolk and Norwich University Hospital, Colney Lane, \\ Norwich NR4 7UY, UK
}

Received 9 February 2005; accepted 2 April 2005

\section{KEYWORDS}

Referral letter;

GP with Special !n'erals:

Chronic obstricive

pulmonary disease;

Commissioning

\section{summararal Practice Aibited}

Ains The purpose of this ofldy was to examine the proportion of general practitioner (GP) (retserrals to a hospital Respiratory Medicine clinic which might beculitable cor a General Practitioner with a Special Interest (GPwSI) Respiratory Cinicl.

Method: All GP referral letters to the Respiratory Medicine Department of a teaching hospital, apart from urgent cancer referrals, were identified from two two-week periods. All patient and practice identifications were removed. Two GPs and one Consultant Respiratory Physician assessed each of the anonymised referral letters to determine the patient's suitability to be seen in a GPWSI Respiratory Clinic, assuming such a clinic had a predetermined range of investigative facilities.

Results: Out of 96 referrals covering a wide range of respiratory conditions apart from lung cancer, 22 (23\%) were considered by all assessors to be suitable for a GPwSI clinic, and there was full agreement that 40 referrals (42\%) were unsuitable. The other 34 referrals (35\%) had varying degrees of agreement on suitability. The largest groups of patient referrals considered suitable for a GPwSI clinic were those with chronic obstructive pulmonary disease (COPD) or cough as the main presenting clinical problem. The commonest groups considered unsuitable were referrals of patients with an abnormal chest radiograph, haemoptysis, or possible interstitial lung disease.

\footnotetext{
* Corresponding author. Tel.: +44 (0) 1603 443300; fax: +44 (0) 1603446012.

E-mail address: richard.gilbert@nhs.net (R. Gilbert).
} 
Conclusion: This small study has shown that at least a fifth of GP referrals to a hospital Respiratory Medicine clinic could be seen in a suitably resourced GPwSI clinic, with consequent reductions in hospital outpatient waiting lists and improved accessibility for patients. This finding will be of interest to potential commissioners of GPWSI services especially with the advent of Practice-based Commissioning.

(C) 2005 General Practice Airways Group. Published by Elsevier Ltd. All rights reserved.

\section{Introduction}

The UK Government's National Health Service Plan proposed the introduction of 'General Practitioners with a Special Interest' (GPwSIs) to contribute to reductions in hospital waiting times and to provide treatment for patients in the community [1]. The concept has subsequently been expanded to include specialist nurses and other allied health professionals (Practitioners with a Special Interest, PwSIs) in addition to GPs [2]. "GPwSl's will supplement their generalist role by delivering a high quality, improved access role to meet the needs of a single PCT or group of PCTs. They may deliver a clinical service beyond the normal scope of general practice, undertake procedures or develop services" [3]. A number of clinical areas have been identified where GPwSI/PwSI services could be developed, including respiratory medicine, and guidelines have been published on the scope of the GPwSI role in respiratory neulcine $[4,5]$ including rockiedciidation and aprirailal [6].

The current study arose but of work on chronic obstructive pulmonary disease (COPD) patient pathways in Central Norfolk carried out as part of the NHS Modernisation Agency "Pursuing Perfection" programme. Whilst working in both primary and secondary care, one of the authors (RG) felt that a significant proportion of referrals to a secondary care Respiratory Medicine outpatient department, particularly of patients with COPD and asthma, could be dealt with in a community setting. Patients would benefit through them being seen quicker and closer to their homes, and this would also help reduce pressure on hospital outpatient waiting lists. This study was devised in order to assess what proportion of GP referrals to a Respiratory Medicine department could be dealt with in a GPwSI clinic which had a predetermined range of facilities.

\section{Method}

This study assessed GP referrals to the Department of Respiratory Medicine at the Norfolk and Norwich
University Hospital (NNUH), a 989-bed teaching hospital serving a population of more than 570,000 people in central Norfolk. The Department receives approximately 1250 new GP referrals each year. In October 2004, 10\% of patients had waited more than 13 weeks for their first outpatient appointment and $37 \%$ had waited more than 8 weeks, according to information from the Norfolk and Norwich University Hospital Information Services.

Consecutive GP referral letters during two two-week periods were identified retrospectively (January 2004) and prospectively (June 2004). These two periods were chosen in case there was any difference in the type of referrals made in summer and winter. Cancer referrals and consultant-to-consultant oreferals were excluded. Copies pí it/Ereferral letters together with ancompdnying computer printouts and Orvestigation results were anonymised by one investizat of (G) (with all patient and GP practice identifications being removed.

Anonymised referral letters were independently assessed by two GPs (one of whom had a special interest in respiratory medicine) and one Consultant Respiratory Physician. They were asked to assess each letter for suitability to be seen in a GPwSI respiratory clinic without need for involvement of secondary care in investigation or treatment. The assessors graded each letter as being suitable, unsuitable, or containing insufficient information to make a decision. The assessors were also asked to consider whether the referrals suitable for the GPwSI clinic could be seen in either a community-based GPwSI clinic or one based in the hospital. The facilities available in each type of clinic were envisaged as follows:

1. Community GPwSI clinic

- Clinic staffed by GPwSI in Respiratory Medicine, Respiratory Nurse Specialist and Spirometry Technician

- Spirometry including flow-volume loop and reversibility testing

- Pulse oximetry

- Viewing of chest radiograph via computer link to digital image at NNUH 
- Simple exercise testing

- Electrocardiography

2. Hospital GPwSI clinic

- All the above plus:

- Full lung function testing

- Blood gases

- Echocardiography

- Allergy testing

It was suggested that patients who might be considered suitable for the GPwSI clinic would be those with a definite or likely diagnosis of COPD or asthma, and those with chronic cough or dyspnoea with a recent chest radiograph not showing significant focal or interstitial pathology. Patients would not be suitable for the GPwSI Clinic if they were likely to require bronchoscopy, CT scan, pleural aspiration or were acutely ill.

The opinions of each assessor on the suitability of each referral were compared. Simple descriptive statistics were used to analyse the agreement between the assessors. For those referrals where there was complete agreement between the assessors, the types of presenting clinical problem were determined.

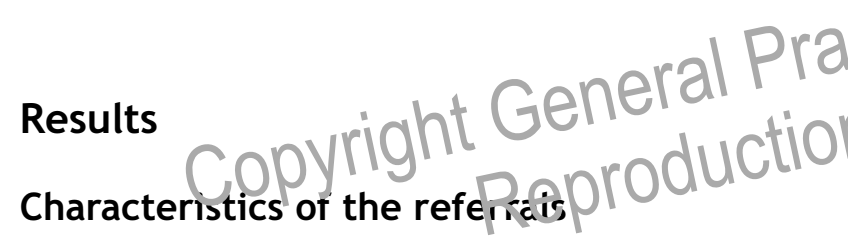

Each two-week period yielded $48 \mathrm{GP}$ referral letters making a total of 96 referrals. The median age of the patients referred was 60.5 (interquartile range 45-69) with 44 males (34-53, 95\% confidence interval), and 52 females (42-62, 95\% confidence interval). The main presenting problems of the referrals are shown in Table 1 . The patients were referred by GPs from five Primary Care Trusts (PCTs).
Table 1 The presenting clinical problems of the patients referred.

\begin{tabular}{ll}
\hline $\begin{array}{l}\text { Presenting clinical } \\
\text { problem }\end{array}$ & $\begin{array}{l}\text { Number }(95 \% \\
\text { confidence interval) }(\%)\end{array}$ \\
\hline Cough & $17(10-24)(18)$ \\
COPD & $16(9-23)(17)$ \\
Dyspnoea & $14(7-21)(15)$ \\
Abnormal chest & $12(6-18)(13)$ \\
$\quad$ radiograph & $7(2-12)(7)$ \\
Haemoptysis & $6(1-11)(6)$ \\
Asthma & $6(1-11)(6)$ \\
$\begin{array}{l}\text { Possible } \\
\text { obstructive sleep }\end{array}$ & \\
apnoea & \\
Possible interstitial & \\
$\quad$ lung disease & $5(1-9)(5)$ \\
Chest pain & \\
Other & $5(1-9)(5)$ \\
\hline
\end{tabular}

\section{Assessment of suitability for GPwSI clinic}

The opinions of the assessors on the suitability of the referrals for a GPwSI clinic are shown in Table 2. All three assessors agreed that 22 referrals (23\%) were suitable for a GPwSI clirif, and of these $36 \%$ were suitable for che Co mminity clinic model, $5 \%$ were donsidered only suitable for the Hospital cinfir, arid the rest were split between the two models ITabis 3\%. There was complete agreement tha: $[40 \%$ of referrals were unsuitable for a GPwSI clinic.

For five referrals there was a lack of agreement between the assessors, or insufficient information to make a decision.

Analysis of the presenting problem within the 62 referrals (65\%) which had complete agreement over suitability showed that the most frequent problems considered suitable for a GPwSI clinic were COPD and cough, whilst the commonest problems considered unsuitable were an abnormal chest radiograph, haemoptysis, and possible interstitial lung disease (Table 4).

Table 2 Opinions of three assessors on suitability for referrals to be seen in a GPWSI Clinic.

\begin{tabular}{lll}
\hline Opinion of assessors & Agreement between assessors & $\begin{array}{l}\text { Numbers of referrals (95\% } \\
\text { confidence interval) (\%) }\end{array}$ \\
\hline Suitable for GPwSI Clinic & Full agreement (3 assessors) & $22(14-30)(23)$ \\
& Partial agreement (2 assessors) & $12(6-18)(13)$ \\
Not suitable for GPwSI Clinic & Full agreement (3 assessors) & $40(31-50)(42)$ \\
& Partial agreement (2 assessors) & $17(10-24)(18)$ \\
No agreement or insufficient information ${ }^{\text {a }}$ & & $5(1-9)(5)$ \\
Total & & 96 \\
\hline a For these five referrals, 0-1 assessors considered suitable for GPwSI clinic in four, 0-1 assessors considered unsuitable in
\end{tabular}


Table 3 Opinion of assessors on suitability of referrals to be seen in a GPwSI Clinic based in the Community or the Hospital.

Opinion of assessors on type of GPwSI Clinic

Number of referrals $(95 \%$ confidence

interval) (\% of study group)

A. Referrals considered suitable for GPwSI Clinic by all assessors
$3 / 3$ Community Clinic
$8(3-13)(36)$
$3 / 3$ Hospital Clinic
$1(-1-3)(5)$
2/3 Community, $1 / 3$ Hospital
$8(3-13)(36)$
1/3 Community, 2/3 Hospital
5 (1-9) (23)

B. Referrals considered suitable for GPwSI Clinic by 2 out of 3 assessors
2/3 Community Clinic
$4(0-8)(4)$
2/3 Hospital Clinic
$4(0-8)(4)$
1/3 Community, $1 / 3$ Hospital
$4(0-8)(4)$

Table 4 The clinical problems in referrals with complete agreement between assessors.

\begin{tabular}{|c|c|c|}
\hline & Clinical Problem & $\begin{array}{l}\text { Number ( } 95 \% \text { confidence } \\
\text { interval) ( } \% \text { of study group) }\end{array}$ \\
\hline \multirow[t]{4}{*}{ Suitable for GPwSI Clinic } & COPD & $11(5-17)(11)$ \\
\hline & Cough & $7(2-12)(7)$ \\
\hline & Asthma & $2(-1-5)(2)$ \\
\hline & Dyspnoea & $2(-1-5)(2)$ \\
\hline \multirow[t]{8}{*}{ Not suitable for GPwSI Clinic } & Abnormal chest radiograph & $11(5-17,11) 0$ \\
\hline & Haemoptysis & $9(2-12)(7)$ \\
\hline & Possible interstitial lung & $5(1-9)(5)$ \\
\hline & Possible obsiruccive slet & $4(0-8)(4)$ \\
\hline & & $4(0-8)(4)$ \\
\hline & & $4(0-8)(4)$ \\
\hline & & $3(0-6)(3)$ \\
\hline & & $2(-1-5)(2)$ \\
\hline
\end{tabular}

\section{Discussion}

This study has shown that at least a fifth of GP referrals to a hospital Respiratory Medicine clinic were considered by three doctors independently to be suitable to be seen in a GPwSI Respiratory Clinic. This proportion may be an under-estimate since a further $12.5 \%$ of referrals were considered suitable by two out of three assessors. Furthermore, some referrals considered unsuitable or considered to contain insufficient information by one or more assessors may have been able to be seen in a GPwSI clinic if more information had been provided with the original referral. For a hospital respiratory department receiving 1000 new GP referrals per year, 200 patients could therefore be seen in a GPwSI Clinic thus reducing pressure on hospital outpatient waiting lists and enabling hospital specialists to concentrate on more complex cases.

Clearly this study is limited in being based on the opinions of only three doctors. However, there was complete agreement on two-thirds of the referral letters assessed, and the range of problems included in the sample of referrals encompassed the whole range of respiratory conditions except lung cancer. Implementing a GPwSI Clinic on the basis of these results would clearly need more detailed discussion with both secondary and primary care colleagues concerning the scope of such a clinic.

For the 22 referrals (23\%) where there was full agreement that they were suitable for a GPwSI Clinic, all patients had a diagnosis of COPD or asthma, or had been referred because of cough or dyspnoea without evidence of other significant pulmonary pathology on a chest radiograph. These 22 referrals together with the characteristics of the referral letters, provide the basic information required for a protocol to identify suitable referrals and to inform GPs on the necessary information to include in a referral letter - for example, a recent chest radiograph report. A recent study on asthma referrals [10] has shown that it is possible to obtain 
good agreement between primary and secondary care physicians on the information required in referral letters.

The protocol for this study implied that suitable patients for the GPwSI Clinic were those who could be managed entirely by the GPwSI team. A larger number of patients could be included if the clinic was seen as a triage service which could refer on to secondary care if more complicated investigations were required.

Assessors were asked to indicate whether a referral was suitable for a Community-based GPwSI Clinic or one based in the hospital. This distinction may be somewhat arbitrary if a Communitybased GPwSI Clinic was able to access hospital investigations such as pulmonary function tests and echocardiography in selected patients. Blood gases could also be measured using capillary blood samples taken in the community.

The recent introduction of the new General Medical Services contract for GPs in the UK has provided a focus on chronic disease management in primary care by rewarding GP practices financially for providing evidence-based care for patients with specified chronic diseases including COPD. Primary care teams are required to make the diagnosis of COPD using spirometry and to provide regular follow-up. Referrals from primary care of COPP patients may increase in the future asa esult of diagnostic uncertainty an w for adised on optimising treatment. im acd tidn, improved iden $\mathrm{c}$ fid atjon of patients vith severe disease vi D lead to more referrals for assessment for nebuliser therapy, oxygen therapy, and pulmonary rehabilitation. Many of these could potentially be dealt with in a GPwSI Clinic.

The financial aspects of a GPwSI service are important especially with the advent of Practicebased Commissioning [7,8]. Up till now, PCTs have not been able to commission new services without new sources of funding or diverting money from existing funding streams. Practice-based Commissioning allows individual practices or groups of practices to commission services directly for their patients with primary and secondary care providers. This is occurring in parallel with "Payment by Results" where hospital trusts are paid for each item of care delivered [9]. As a basis for contracting between primary and secondary care, there will be National Tariffs from 2006 for each type of activity. For Respiratory Medicine outpatient visits, the National Tariffs will be $£ 178$ for first attendance and $£ 123$ for follow-ups. A GPwSI clinic could be set up with considerably lower overheads compared to a hospital clinic. A GPwSI Clinic with a GPwSI and nurse specialist seeing six new and 10 follow-up patients in a session (worth $£ 2298$ at National Tariff rates) might only cost approximately $£ 600$ per session (excluding accommodation and capital costs) thus yielding considerable savings to commissioners. The assessment of potential economic benefits of GPwSI services is complex, however, and has been discussed in detail by Kernick $[11,12]$.

The GPwSI in Respiratory Medicine role as outlined in this study has been considered purely in terms of service delivery. Williams et al. [13] described a broader role for GPwSls as part of a primary care team improving respiratory disease management in a locality. The national guideline on GPwSIs in Respiratory Medicine envisages a variety of other potential roles including development of community-based services (for example, pulmonary rehabilitation), providing education and prescribing advice, and acting as a Clinical Lead within a PCT to develop respiratory care in general [4].

Over one thousand GPwSIs are now in post across the country in a variety of specialties with reported benefits in terms of improved access to services for patients [14]. GPwSIs in Respiratory Medicine are now in post in a number of places $[15,16]$, and this study provides furticencidence to support their establian ment more widely. There has been chlicem expressed that GPWSI services are being developed vinouvidence of their effectiveness [17]) [ard it is important that pilot GPwSI projects should be evaluated carefully. The principle of a cost-effective respiratory GPwSI service in the community also has wider applicability to a range of specialties where GPwSls with appropriate skills and experience are available.

\section{Acknowledgements}

Norwich PCT provided some locum funding for this study.

Thanks to the colleagues who contributed to this study in assessing the referral letters, to Prof. David Price for helpful comments on the manuscript and to Dr Louise Swift for statistical advice.

\section{References}

[1] Department of Health. The NHS Plan, 2000. (www.dh. gov.uk/assetRoot/04/05/57/83/04055783.pdf, accessed 1/2/2005).

[2] Department of Health. Practitioners with special interests: bringing services closer to patients, 2003. (www.dh.gov.uk/ assetRoot/04/07/23/69/04072369.pdf, accessed 1/2/ 2005). 
[3] Department of Health/Royal College of General Practitioners. Implementing a Scheme for General Practitioners with Special Interests, 2002. (www.dh.gov.uk/ assetRoot/04/05/98/61/04059861.pdf, accessed 1/2/ 2005).

[4] Department of Health/Royal College of General Practitioners. Guidelines for the appointment of General Practitioners with Special Interests in the Delivery of Clinical Services: Respiratory Medicine, 2003. (www.dh. gov.uk/assetRoot/04/06/83/77/04068377.pdf, accessed $1 / 2 / 2005)$.

[5] Working party of General Practice Airways Group, and the Royal College of General Practitioners, General practitioners with a special interest in respiratory medicine. Primary Care Resp J 2003;12(2):38-41.

[6] Gruffydd-Jones K. Accreditation and appraisal of the general practitioner with a special interest in respiratory medicine. Primary Care Resp J 2003;12(4):107.

[7] Department of Health. Practice Based Commissioning, 2004. (www.dh.gov.uk/assetRoot/04/09/85/65/04098565. pdf, accessed 1/2/2005).

[8] Lewis RQ. Back to the future? BMJ 2004;329:932-3.

[9] Department of Health. Payment by Results, 2004. (www.dh.gov.uk/PolicyAndGuidance/OrganisationPolicy/ FinanceAndPlanning/NHSFinancialReforms/fs/en, accessed 1/2/2005).
[10] Tuomista L, Erhola M, Kaila M, et al. Asthma Programme in Finland: High consensus between general practitioners and pulmonologists on the contents of an asthma referral letter. Primary Care Resp J 2004;13(4):205-10.

[11] Kernick $D$. The economic perspective of respiratory general practitioners with a special interest (GPwSIs): proceed with caution. Primary Care Resp J 2003;12(4):108-9.

[12] Kernick D. Developing intermediate care provided by general practitioners with a special interest: the economic perspective. Br J Gen Pract 2003;53(7):553-6.

[13] Williams S, Ryan D, Price D, Langley C, Fletcher M, Everden P. General Practitioners with a special clinical interest: a model for improving respiratory disease management. $\mathrm{Br} \mathrm{J}$ Gen Pract 2002;52(10):838-43.

[14] Department of Health 2003. More than 1000 special interest GP's now delivering treatment in the community. Press release $14 / 8 / 2003$

[15] O'Kelly N, Baldy D, Young K. Reduction of hospital admissions with an integrated COPD Programme in East Lincolnshire. Thorax 2004;59(Suppl. II):ii48.

[16] General Practitioner Airways Group. GPwSI resource pack 2005. www.gpiag.org.

[17] Smith $H$. Connecting rhetoric, reality and research: the need for evaluation of General Practitioners with Special Interests. Primary Care Resp J 2005;14(1):3-4.

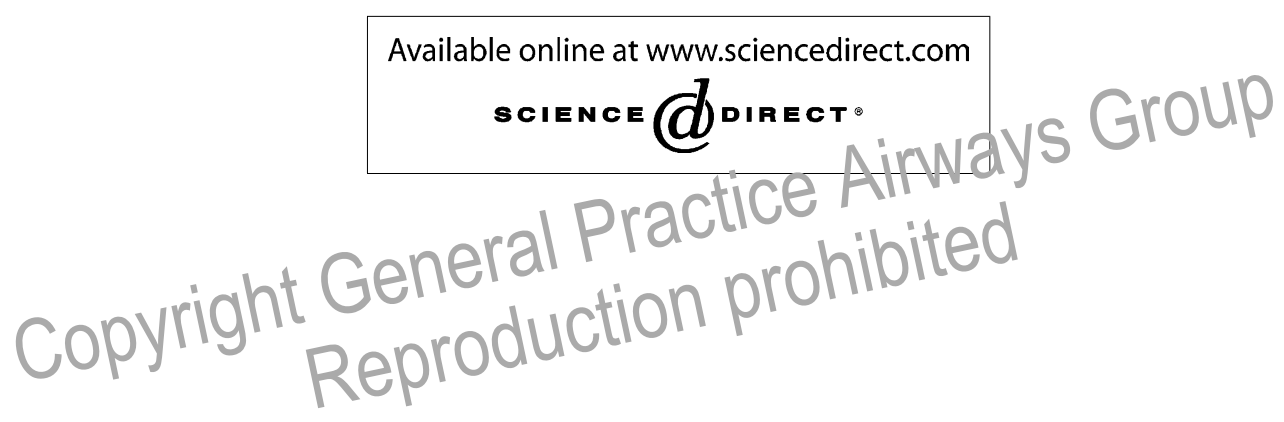

Available online at http://www.thepcrj.com 